\title{
Aleksinin Eşlik Ettiği Gerstmann Sendromu Olgusu
}

\section{A Case of Gerstmann Syndrome with Alexia \\ Abdulkadir Tunç, Yonca Ünlübaş}

Sakarya Üniversitesi, Sakarya Eğitim ve Araştırma Hastanesi, Nöroloji Kliniği Sakarya/Türkiye

Yazıșma Adresi / Correspondence: Abdulkadir Tunç

Sakarya Üniversitesi, Sakarya Eğitim ve Araştırma Hastanesi, Nöroloji Kliniği, SAKARYA

T: +90554514 $4524 \quad$ E-mail: drkadirtunc@hotmail.com

Geliş Tarihi / Received : 01.11.2018 Kabul Tarihi / Accepted : 20.11.2018

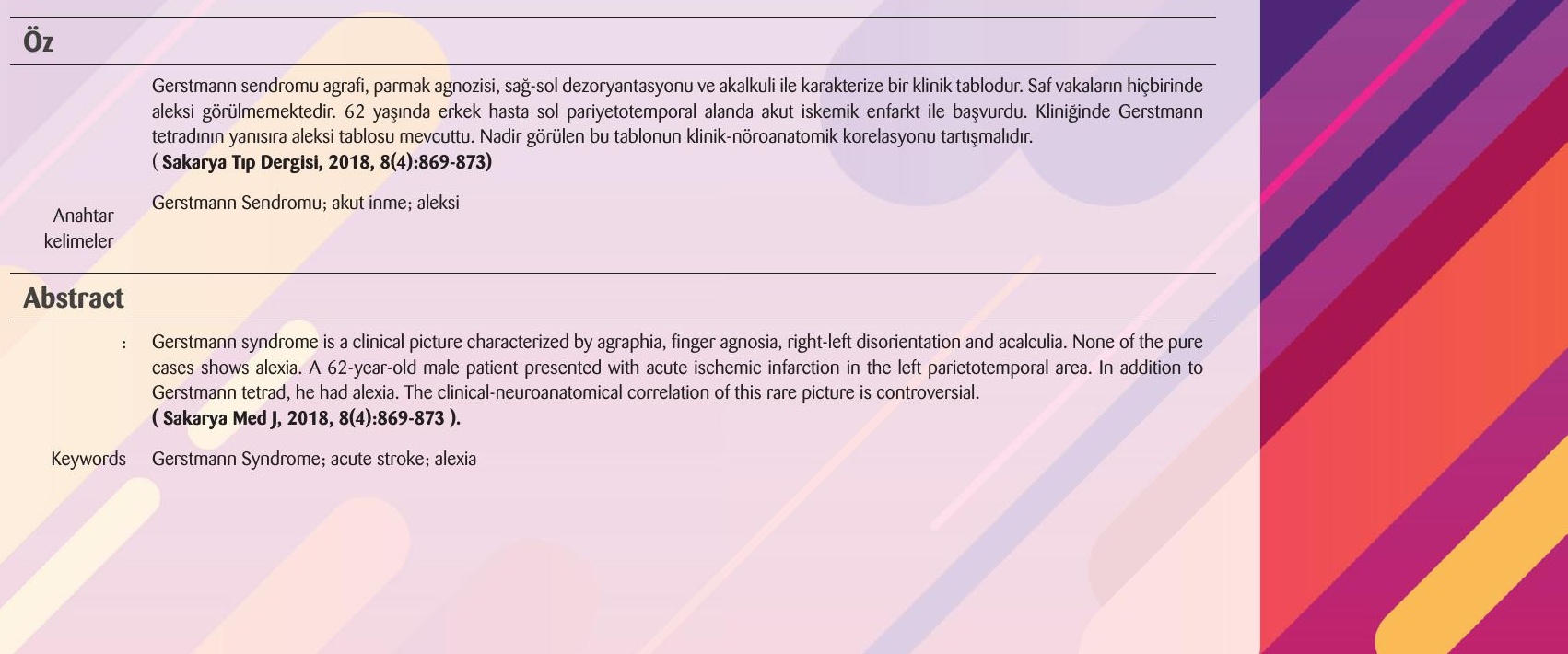


Sakarya TIp Dergisi 2018;8(4):869-873

TUNC ve Ark. Aleksinin Eslik Ettiğgi Gerstmann Sendromu Olgusu

\section{Giriş}

Gerstmann sendromu (GS), sol hemisfer pariyetal lobda ve özellikle angular girus lokalizasyonunda meydana gelen lezyonların neden olduğu spesifik bir tabloyu tanımlar. Sıklıkla inme sonrası görülen bu tabloda klasik olarak tanımlanan 4 bulgu mevcuttur. Bunlar agrafi, parmak agnozisi, sağ-sol dezoryantasyonu ve akalkuliden oluşur. ${ }^{1}$ Bununla birlikte, nadiren saf formda ortaya çıtığı için GS, diğer bazı semptom kombinasyonlarına kıyasla fokal parieto-temporo-oksipital hastalığın tanısal bir göstergesi olarak daha az yararlıdır. ${ }^{2}$ Bazı çalışmalar, GS’ nin klinik semiyolojiyi destekleyen ortak bilişsel fonksiyonlara verilen hasar ile uyuşmadığını bildirmektedir. Fonksiyonel nöroanatomiden elde edilen kanıtlar, Gerstmann tetradının saf formlarının lezyondan, ortak kortikal bir substrata değil, subkortikal beyaz cevherdeki fokal bir bölgedeki hasara bağlı intraparietal diskonneksiyondan kaynaklandığını düşündürmektedir. ${ }^{3}$ Literatürde Gerstmann tetradına eşlik eden aleksi, depresyon, bellek zayıflığı, hayal kırıklığı ve ajitasyon gibi davranışsal belirtileri içeren tablo angular girus sendromu olarak tanımlanmıştır. ${ }^{4}$ Sol temporal lobda yer alan angular girus, Broca ve Wernicke alanlarını da içeren beynin lisan sisteminin bir parçasıdır. ${ }^{5}$ Bu yazımızda sol temporopariyetal alanda akut iskemik enfarkt ile prezente olan ve Gerstmann tetradına ek olarak aleksi kliniği olan bir olgu sunup literatür eşliğinde tartışmayı amaçladık.

\section{Olgu Sunumu}

62 yaşında sağ elini kullanan erkek hasta, ani gelişen bilinç bozukluğu nedeniyle acil servisimize getirildi. Hastanın özgeçmişinde hipertansiyon tanısı mevcut olup düzenli ilaç kullanımı yoktu. Üç ay önce geçici iskemik atak geçirdiği öğrenildi. Sigara, alkol veya madde kullanım öyküsü yoktu. Soy geçmişinde de özellik saptanmadı. Hastanın başvuru anında tansiyon yüksekliği mevcuttu (185/110 mm/Hg), EKG'si normal sinüs ritmindeydi. Nörolojik muayenesinde hastanın bilinci açık, koopere ve oryante idi. Kranial sinir muayenesi normaldi. Ense sertliği veya meningeal irritasyon bulgusu saptanmadı. Kas güçleri tamdı. Konuşma akıcı idi, anlaması tamdı. Serebellar sistem muayenesi normaldi. Taban cildi refleksi sağda lakayt alındı. Hasta okuyamadığını ifade etmesi üzerine yapılan değerlendirmede aleksi ve agrafisi saptandı. Eşlik eden sağ-sol dezoryantasyonu, akalkuli ve parmak agnozisi de detaylı nörolojik muayenesinde tespit edildi. Acil serviste çekilen difüzyon ağırlıklı magnetik rezonans görüntülemesinde sol alt pariyetal lobda angular girusu da içine alan akut iskemik enfarkt ile uyumlu hiperintensite saptandı (Resim 1a,1b).
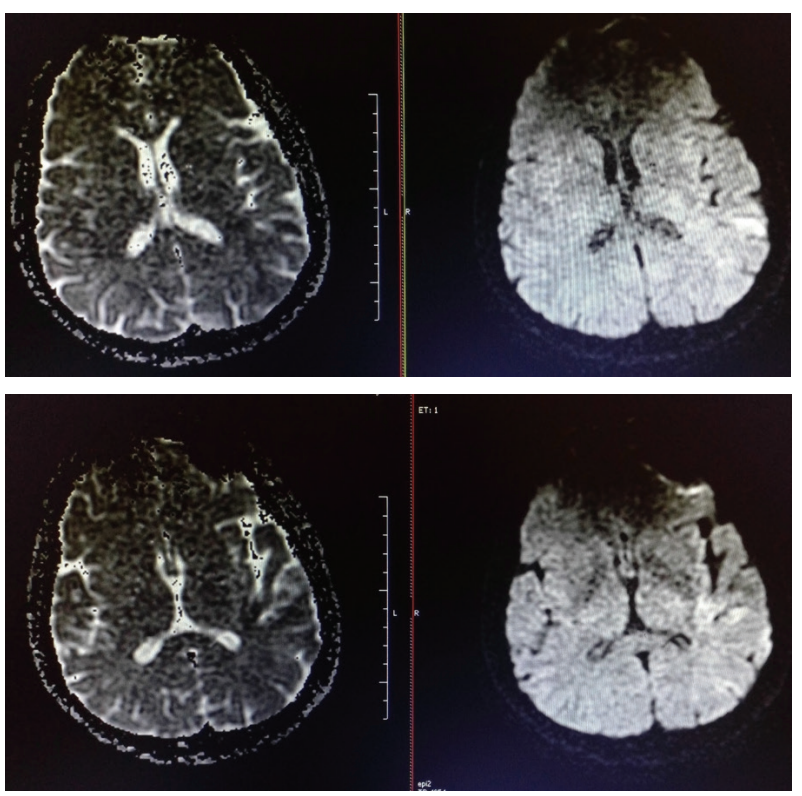

Resim 1a,1b. Sol temporal alanda insüler kortekse uzanan difüzyon ağılıklı görüntülemelerde hiperintens, ADC görüntülerde hipointens akut iskemik enfarkt ile uyumlu difüzyon kısıtlılığı 
Beyin bilgisayarlı tomografisinde (BT) sinde akut patoloji saptanmadı. Akut evreyi geçtiğinden trombolitik tedavi verilmedi. Karotis+ beyin BT angio'sunda kritik darlık görülmeyen hasta tekli antiagregan ve antihipertansif tedavi ile servisimize interne edildi. Etyolojik değerlendirmesi detaylı yapılan hastanın laboratuvar değerlerinde belirgin patoloji saptanmadı. Transtorasik ekokardiyografisinde sol atriyal dilatasyon ve sol ventrikül hipertrofisi saptandı. 24 sa ritm holter takılan hastada atrial fibrilasyon saptanmadı. Karotis arterler doppler ultrasonografi ile de değerlendirildi, sol karotis komunis ile internal karotis proksimali düzeyinde yaklaşık \%30 darlı̆a neden olan kalsifik plak formasyonu saptandı. Kliniği stabil seyreden hasta 1 haftalık takibin sonunda eksterne edildi. 1. ay poliklinik kontrolünde klinik bulgularında hafif düzelme gözlendi. Kontrol beyin BT' sinde sol temporopariyetalde yerleşmiş hipodens enfarkt alanı görüldü (Resim 2).

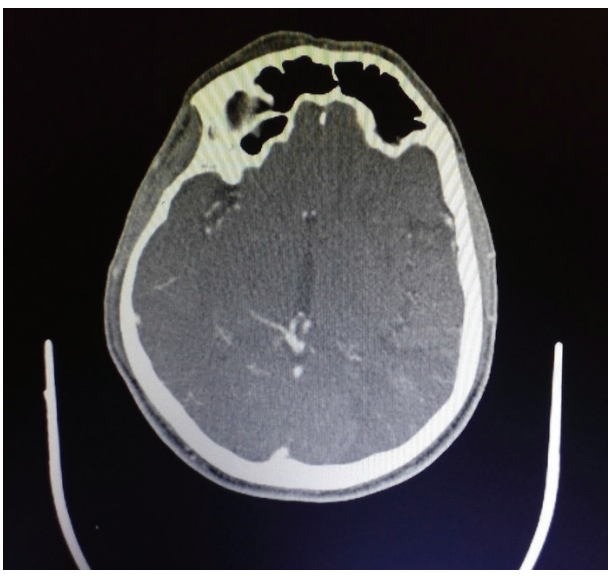

Resim 2. 1. Ay BT kontrolünde sol pariyetotemporal alanda yerleşmiş hipodens enfarkt alanı

\section{Tartışma}

Gerstmann sendromu, vücut algııının bozulması sonucu düşünceleri yazılı olarak ifade etme yeteneği (agrafi), basit aritmetik problemlerin hesaplanması (akalkuli), kişinin kendi ya da başkalarının parmaklarını tanıması (parmak agnosisi) ve sağ-sol arasında bir ayrım yapma becerisinin yitirilmesi ile karakterizedir. ${ }^{6}$ Hastamızda klasik tetrad mevcuttu. Aleksi kliniği daha çok rakamları okuma şeklinde idi ve matematiksel sembollerle ilgili zorlukları vardı. Buna karşlık anomi yoktu ve aritmetik simgelerin tanınmasındaki güçlük dışında, nesnelerin isimlerini ve işlevlerini, nesne parçalarını, renkleri veya geometrik figürleri adlandırma konusunda herhangi bir güçlüğü yoktu. Gerstmann'ın agrafisi, el yazısı ile sınırıdır ve yapısal apraksi ve ekstremite apraksisi ile birlikte görülmemektedir. Saf vakaların hiçbirinde aleksinin görülmeyeceği bildirilmiştir. ${ }^{6}$

Gerstmann sendromu kliniğini oluşturan tetradın bir otonom kombinasyon mu olduğu ve her zaman angular girus lezyonunu mu gösterdiği tartışma konusu olmuştur. Literatürde bu otonom kombinasyonun multiple nöronal networkların anatomik yakınlığından kaynaklandığı bildirilmiştir. ${ }^{7}$ Ando ve ark., GS' nin sadece sol angular girusun disfonksiyonundan değil aynı zamanda dominant hemisferdeki orta frontal girusdan da kaynaklanabileceğini bildirmiştir. ${ }^{8}$ Rusconi ve ark., Gerstmann'ın hipotezini, bir grup sağlıkı bireyin fonksiyonel ve yapısal nörogörüntülemesini yaparak test etmiş ve Gerstmann tetradının işlevsel değil yapısal olduğunu ileri sürmüştür. ${ }^{3}$ Dört alanı temsil eden yerlerden ayrı, konverjan liflerindeki bir lezyon sonucu oluşan diskonneksiyonun bu tabloya neden olduğu saptanmıştır. Bu bulgular dominant pariyetal lobdaki hasarın klinik sonuçlarına ilginç bir ışık tutmuştur. Ne Gerstmann sendromunun kardinal belirtileri ne de beyaz cevherin bu bölgelerdeki lezyonları nadir değildir, fakat saf GS’ deki seçici asosiyasyonlar nadiren görülen
Sakarya Tıp Dergisi $2018 ; 8(4): 869-873$

TUNÇ ve Ark. Aleksinin Eșlik Ettigig Gerstmann Sendromu Olgusu 
bir klinik bir tabloyu ifade eder. ${ }^{3}$

GS nadir görülen bir klinik tablodur ve lokalize edici değeri ile ilgili olarak bu vaka, hastalığın dominant parietotemporal lobdaki hasarla ilişkili olduğunu doğrulamıştır. Ancak eşlik eden aleksi, görüntülemelerinde angular girus lezyonu görülmediğinden ve bu bölgenin tutulumunda görülen depresyon, bellek zayıflığı, hayal kırıklı̆ı ve ajitasyon gibi davranışsal belirtilerin olmayışı nedeniyle ilginç bulunmuştur. Şüphesiz GS hem klinik nörologları hem de nöropsikolojide araştırmacıları etkilemeye devam edecektir. 
1. Benton AL Gerstmann`s syndrome. Arch Neurol. 1992:49:445-447.

2. Zukic S, Mrkonjic Z, Sinanovic O, Vidovic M, Kojic B. Gerstmann's syndrome in acute stroke patients. Acta Inform Med. 2012 Dec;20(4):242-243.

3. Rusconi E, Pinel P, Eger E, et al. A disconnection account of Gerstman syndrome: functional neuroanatomy evidence. Ann Neurol. 2009; 66(5) 654-662.

4. Nagaratnam N, Phan TA, Barnett C, Ibrahim N. Angular gyrus syndrome mimicking depressive pseudodementia. J Psychiatry Neurosci. 2002 Sep;27(5):364-368.

5. Greenblatt SH. Alexia without agraphia or hemianopsia. Anatomical analysis of an autopsied case. Brain 1973;96:307-316.
6. Rusconi E. Gerstmann syndrome: historic and current perspectives. Handb Clin Neurol. 2018;151:395-411

7. Wingard EM, Barrett AM, Crucian GP, Doty L, Heilman KM. The Gerstmann syndrome in Alzheimer's disease. J Neurol Neurosurg Psychiatry. $2002 \mathrm{Mar} ; 72(3): 403-405$

8. Ando Y, Sawada M, Morita M, Kawamura M, Nakano I. Incomplete Gerstmann syndrome with a cerebral infarct in the left middle frontal gyrus. Rinsho Shinkeigaku. 2009. 49(9): 560-565.
Sakarya Tıp Dergisi

2018;8(4):869-873

\section{TUNÇ ve Ark.}

